\title{
The Relationship between Invasive Hemodynamic Measurements and Tissue Doppler-Derived Myocardial Velocity and Acceleration during Isovolumic Relaxation in Healthy Dogs
}

\author{
Yasutomo HORI ${ }^{1) *}$, Shoh-ichi KUNIHIRO ${ }^{1)}$, Kazutaka KANAI ${ }^{1)}$, Fumio HOSHI ${ }^{1)}$, Naoyuki TTOH $^{1)}$ and \\ Sei-ichi HIGUCHI ${ }^{1)}$ \\ ${ }^{1)}$ Department of Small Animal Internal Medicine, School of Veterinary Medicine, Kitasato University, 23-35-1 Higashi, Towada, Aomori \\ 034-8628, Japan
}

(Received 12 December 2008/Accepted 17 June 2009)

\begin{abstract}
This study investigated the feasibility of using the values of tissue Doppler imaging (TDI)-derived myocardial velocity during isovolumic relaxation $\left(\mathrm{V}_{\mathrm{IR}}\right)$ and myocardial acceleration during isovolumic relaxation (ACC) obtained from the left ventricular (LV) free wall to evaluate LV relaxation in normal dogs. Seven dogs were anesthetized, and dobutamine or esmolol was infused at a rate of 5.0 and $10.0 \mu \mathrm{g} / \mathrm{kg} / \mathrm{min}$ or 100 and $500 \mu \mathrm{g} / \mathrm{kg} / \mathrm{min}$, respectively, via a cephalic vein. The order of drug administration (dobutamine or esmolol) was assigned to each dog. Simultaneous pulsed-Doppler (PD) echocardiography, TDI and hemodynamic measurements were performed. Compared with the baseline values, dobutamine significantly increased $\mathrm{dP} / \mathrm{dt}$ min, but significantly shortened tau $(\tau)$. Similarly, esmolol significantly decreased $\mathrm{dP} / \mathrm{dt} \mathrm{min}$, but significantly prolonged $\tau$. Compared with the baseline values, dobutamine significantly increased $V_{I R}$ and ACC, and esmolol significantly decreased $V_{I R}$ and ACC. Both $\mathrm{dP} / \mathrm{dt}$ min and $\tau$ were significantly correlated with TDI-derived IVRT $(r=0.43$ and 0.74$), \mathrm{V}_{\mathrm{IR}}(r=0.85$ and -0.49$)$ and ACC $(r=0.84$ and -0.52$)$. These results indicate that the TDIderived $\mathrm{V}_{\mathrm{IR}}$ and ACC values obtained from the LV free wall can potentially be used to assess LV relaxation in dogs.
\end{abstract} KEY WORDS: canine, diastolic function, left ventricle, tissue Doppler imaging.

J. Vet. Med. Sci. 71(11): 1419-1425, 2009

Impaired relaxation is common in human patients and dogs with chronic heart failure [1, 5, 10, 27, 29]. Information regarding left ventricular (LV) diastolic function can be used to assess disease severity and prognosis in patients with heart failure $[21,23]$. Several parameters measured by tissue Doppler imaging (TDI)-derived early and late diastolic myocardial velocities are indicators of diastolic function in dogs, providing diagnostic information and describing the severity of heart disease $[4,6,29]$. Similarly, TDI-derived isovolumic relaxation time (IVRT) can potentially be used as an indicator of LV diastolic function in humans and dogs with heart disease [3, 9, 17, 28].

Recently, strain rate imaging-derived myocardial velocity during isovolumic relaxation $\left(\mathrm{V}_{\mathrm{IR}}\right)$ was found to be a useful parameter for dyskinesis in an animal model with myocardial ischemia [8]. Similarly, $\mathrm{V}_{\mathrm{IR}}$ detected by pulsedTDI may be a useful indicator of ischemia in patients with coronary artery disease [25]. Furthermore, Hashimoto et al. reported that strain rate imaging-derived myocardial acceleration during isovolumic relaxation (ACC) is correlated with ventricular diastolic function and is independent of preload in sheep $[12,13]$. Because strain rate imaging measures only the velocity contribution from the myocardium, it may reflect regional function only. In contrast, because TDI measures velocity resulting from all longitudinal motion between the point of measurement and the ultrasound trans-

\footnotetext{
* Correspondence to: Hori, Y., Department of Small Animal Internal Medicine, School of Veterinary Medicine, Kitasato University, 23-35-1 Higashi, Towada, Aomori 034-8628, Japan. e-mail: hori@vmas.kitasato-u.ac.jp
}

ducer, it is likely to reflect global cardiac function. Thus, pulsed-TDI-derived $\mathrm{V}_{\mathrm{IR}}$ and ACC may be used as an additional screening method to identify diastolic function in dogs. However, the relationship between invasive measurements of LV diastolic function and pulsed-TDI-derived $V_{I R}$ and ACC measurements in dogs is unknown.

Thus, the purpose of this study was to investigate the feasibility of using pulsed-TDI-derived $V_{I R}$ and ACC measurements obtained from the LV free wall to evaluate LV relaxation in normal dogs.

\section{MATERIALS AND METHODS}

Animals: Seven healthy mongrel male dogs that were 1 to 5 years old and weighed 7 to $15 \mathrm{~kg}$ were used in this study. The dogs were housed individually in cages and fed commercial dry food with free access to water. The study followed the Guidelines for Institutional Laboratory Animal Care and Use of the School of Veterinary Medicine at Kitasato University, Japan.

Each dog was anesthetized with propofol $(6.0 \mathrm{mg} / \mathrm{kg}, \mathrm{IV})$ and intubated following sedation with butorphanol $(0.2 \mathrm{mg} /$ $\mathrm{kg}, \mathrm{IV})$ and atropine $(0.025 \mathrm{mg} / \mathrm{kg}, \mathrm{SC})$. Anesthesia was maintained with $2.0 \%$ isoflurane in oxygen. The dog was positioned in left lateral recumbency. Respiratory rate was maintained with an artificial ventilator (KV-1a, Kimura Medical Instrument Co., Ltd., Tokyo, Japan), and the arterial partial pressure of carbon dioxide $\left(\mathrm{PaCO}_{2}\right)$ and heart rate were monitored. Under fluoroscopic guidance, a highfidelity 3.5-F micromanometer-tipped catheter (Model 
SPR-524, Millar Instruments, Houston, TX, U.S.A.) was placed through the right carotid artery into the LV. The peak systolic left ventricular pressure (LVPs), end-diastolic left ventricular pressure (LVEDP), time constant of isovolumic relaxation (tau; $\tau$ ) and peak positive and negative first derivatives of the LV pressure $(\mathrm{dP} / \mathrm{dt} \max$ and $\mathrm{dP} / \mathrm{dt} \mathrm{min}$, respectively) were recorded continuously. Hemodynamic data were recorded using the commercial analysis software package supplied with the system (Notocord HEM 3.1 software; Croissy sur Seine, France).

After completing the procedures, a 20- to 30-min stabilization period was allowed to establish a baseline condition for the hemodynamic and echocardiographic measurements.

Drug administration: Dobutamine (Dobutrex ${ }^{\circledR}$, Shionogi $\&$ Co., Osaka, Japan) was infused at a rate of 5.0 or $10 \mu \mathrm{g} /$ $\mathrm{kg} / \mathrm{min}$ for $5 \mathrm{~min}$ via a cephalic vein [23]. Similarly, esmolol (Brevibloc ${ }^{\circledR}$, Maruishi Pharmaceutical Co., Ltd., Osaka, Japan) was infused at a rate of 100 or $500 \mu \mathrm{g} / \mathrm{kg} / \mathrm{min}$ for $5 \mathrm{~min}$ via a cephalic vein [3]. The adrenergic agents were dissolved in sterile saline and administered with an infusion pump. Four dogs were administered dobutamine and esmolol, and three dogs were administered esmolol and dobutamine. After completing the first drug, a stabilization period of at least $30 \mathrm{~min}$ was provided to reestablish a baseline condition. Following baseline recording, the other drug was administered.

Echocardiography: Standard pulsed-Doppler (PD) and TDI velocities were obtained from the apical long-axis view. Transthoracic echocardiography was performed using an ultrasonographic system (SONOS 5500 system, Hewlett Packard, Littleton, MA, U.S.A.) with a $12-\mathrm{MHz}$ probe. Time-interval measurements were made using the internal analytical package of the ultrasound unit. The mean values of 3 consecutive cardiac cycles were calculated to obtain the PD and TDI measurements.

PD echocardiography (filter, $600 \mathrm{~Hz}$; gain, 60\%; sweep speed, $100 \mathrm{~mm} / \mathrm{sec}$ ) was used to measure the transmitral flow (TMF) velocity with the sample volume positioned at the tip of the opened mitral valve leaflets. The peak E wave and peak $\mathrm{A}$ wave TMF velocities were measured, and the ratio of the $\mathrm{E}$ wave to the $\mathrm{A}$ wave (E/A ratio) was calculated. The ejection time (ET) was measured from onset to the end of aortic outflow. PD-derived IVRT was calculated by subtracting the time interval between the peak of the $\mathrm{R}$ wave and the end of the ET from the time interval between the peak of the $\mathrm{R}$ wave and the onset of the E wave [7, 11]. The isovolumic contraction time (IVCT) was calculated by subtracting the ET and PD-derived IVRT from the time interval between the cessation of the mitral valve A wave and the onset of mitral valve $\mathrm{E}$ wave in the next cardiac cycle [7, $11]$.

The TDI program was adjusted from the standard PD mode. The filter was set to $50-100 \mathrm{~Hz}$ and was adjusted to exclude high-frequency signals. The gain was set to 10 $20 \%$ and was minimized to allow for a clear signal with minimal background noise. The sweep speed was $100 \mathrm{~mm} /$ sec. A 2-mm sample volume was placed at the LV free wall

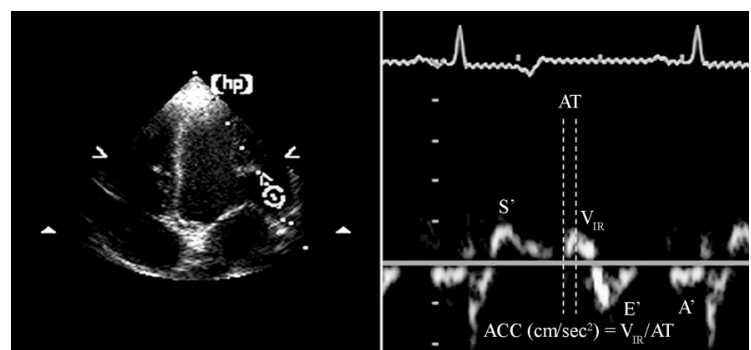

Fig. 1. Tissue Doppler imaging (TDI)-derived $\mathrm{V}_{\mathrm{IR}}$ and ACC. S': mitral annular systolic velocity. E': mitral annular early diastolic velocity. A': mitral annular late diastolic velocity. $\mathrm{V}_{\mathrm{IC}}$ : mitral annular velocity during isovolumic contraction. $\mathrm{V}_{\mathrm{IR}}$ : mitral annular velocity during isovolumic relaxation. ACC: mitral annular acceleration during isovolumic relaxation. AT: acceleration time.

of the mitral valve annulus, and the peak myocardial velocity was measured during systole (S'), early diastole (E') and late diastole (A'). The ratio of the E' wave to the A' wave (E'/A' ratio) was subsequently calculated. The duration of the $S^{\prime}$ wave was measured from the onset to the end of the S' wave. The duration of the TDI-derived IVCT was measured from the end of the A' wave to the onset of the $S$ ' wave [21]. Similarly, the TDI-derived IVRT was measured from the end of the S' wave to the onset of the E' wave [3]. $\mathrm{V}_{\text {IR }}$ was measured as the peak velocity of the positive wave between the end of the systolic ejection phase and the beginning of the early diastolic relaxation phase (Fig. 1) [19, 25]. The presence of $\mathrm{V}_{\mathrm{IR}}$ was judged as a positive wave in all dogs and situations. ACC, which is the slope of the upstroke of the isovolumic relaxation wave, was calculated as the peak $\mathrm{V}_{\mathrm{IR}}$ divided by the acceleration time, which was measured from the onset to the peak velocity of $V_{\text {IR }}$ (Fig. 1). The intra- and inter-assay coefficients of variation (CV) for $\mathrm{V}_{\mathrm{IR}}$ and ACC are shown in Table 1.

Table 1. Intra- and inter-assay coefficients of variation for $\mathrm{V}_{\mathrm{IR}}$ and ACC in healthy dogs

\begin{tabular}{lcccc}
\hline CV values & Observer $(\mathrm{n})$ & $\operatorname{Dog}(\mathrm{n})$ & $\mathrm{V}_{\mathrm{IR}}(\%)$ & $\mathrm{ACC}(\%)$ \\
\hline Intra-day & 1 & 5 & 11.3 & 11.5 \\
Inter-day & 1 & 4 & 9.6 & 14.8 \\
Inter-observer & 3 & 5 & 6.8 & 14.5 \\
Intra-observer & 1 & 5 & 5.0 & 12.4 \\
\hline
\end{tabular}

$\mathrm{CV}$ values $(\%)=\mathrm{SD}$ values/mean values $\times 100 . \mathrm{V}_{\mathrm{IR}}$ and $\mathrm{ACC}$ were calculated from 3 consecutive cardiac cycles at baseline. The interday $\mathrm{CV}$ values for $\mathrm{V}_{\mathrm{IR}}$ and $\mathrm{ACC}$ were the results from $5 \mathrm{dogs}$ evaluated by a single observer on 3 occasions every other week. The intra-day $\mathrm{CV}$ values for $\mathrm{V}_{\mathrm{IR}}$ and $\mathrm{ACC}$ were the results from $4 \mathrm{dogs}$ evaluated by a single observer on 3 occasions at 8-hr intervals during one day. The inter-observer $\mathrm{CV}$ values for $\mathrm{V}_{\mathrm{IR}}$ and $\mathrm{ACC}$ were the results from 5 dogs. Each dog was evaluated by 3 observer's respectively. The intra-observer $\mathrm{CV}$ values for $\mathrm{V}_{\mathrm{IR}}$ and $\mathrm{ACC}$ were the results from 5 dogs evaluated by a single observer at 3 times on one occasion. CV values were calculated for each dog at each point. CV: coefficients of variation. $\mathrm{V}_{\mathrm{IR}}$ : myocardial velocity during isovolumic relaxation. ACC: myocardial acceleration during isovolumic relaxation. 
Statistical analyses: The data are described as mean \pm standard deviation (SD) values. Changes in the hemodynamic and echocardiographic measurements were compared using a one-factor repeated-measures analysis of variance. Significant differences were tested using of the post-hoc Tukey's multiple comparison test. Spearman's nonparametric correlation analysis was applied to compare the changes in echocardiographic measurements to the changes in $\mathrm{dP} / \mathrm{dt}$ min values and $\tau$. A $P$ value of $<0.05$ was considered significant. Forward stepwise regression analysis was used to determine the hemodynamic parameters that were best correlated with $\mathrm{dP} / \mathrm{dt}$ min or $\tau$. A value of $F>2.0$ was considered statistically significant.

\section{RESULTS}

Compared with the baseline, the heart rate increased significantly with dobutamine at $10 \mu \mathrm{g} / \mathrm{kg} / \mathrm{min}$, whereas it did not change with esmolol (Table 2). Similarly, following dobutamine administration, the LVPs significantly increased from baseline at each dose, whereas the LVEDP remained unchanged. At $500 \mu \mathrm{g} / \mathrm{kg} / \mathrm{min}$ esmolol, the LVPs significantly decreased from baseline, whereas the LVEDP significantly increased. Compared with the baseline value, $\mathrm{dP} / \mathrm{dt}$ max significantly increased following dobutamine administration and decreased significantly with esmolol, regardless of the dose. Similarly, $\mathrm{dP} / \mathrm{dt}$ min was increased significantly with dobutamine and decreased significantly with esmolol, regardless of the dose. All doses of dob- utamine significantly shortened $\tau$ from its baseline value, whereas all doses of esmolol significantly prolonged it.

Although dobutamine increased the $\mathrm{E}$ wave at each dose and the A wave at $10 \mu \mathrm{g} / \mathrm{kg} / \mathrm{min}$, esmolol decreased the E wave at $500 \mu \mathrm{g} / \mathrm{kg} / \mathrm{min}$ and the A wave at each dose (Table 3). Consequently, neither drug affected the E/A ratio. IVCT was shortened significantly following dobutamine administration compared with the baseline, whereas IVRT tended to shorten; the difference, however, was not significant. In contrast, both IVCT and IVRT were significantly prolonged following administration of $500 \mu \mathrm{g} / \mathrm{kg} / \mathrm{min}$ esmolol. ET was significantly shortened by both $10 \mu \mathrm{g} / \mathrm{kg} /$ min dobutamine and $500 \mu \mathrm{g} / \mathrm{kg} / \mathrm{min}$ esmolol.

The effects of the inotropic agents on TDI are shown in Fig. 2 and Table 4. Dobutamine significantly increased the S', E' and A' velocities, whereas esmolol significantly decreased the S' and E' velocities. Consequently, the E'/A' ratio decreased significantly with esmolol at $500 \mu \mathrm{g} / \mathrm{kg} / \mathrm{min}$. Dobutamine significantly shortened the TDI-derived IVCT compared with the baseline, whereas esmolol at $500 \mu \mathrm{g} / \mathrm{kg} /$ min produced a significant prolongation. The TDI-derived IVRT was significantly shorter than the baseline value following administration of $10 \mu \mathrm{g} / \mathrm{kg} / \mathrm{min}$ dobutamine, but it was significantly prolonged by administration of $500 \mu \mathrm{g} / \mathrm{kg} /$ min esmolol. $V_{I R}$ was detected as a positive wave in all dogs. $\mathrm{V}_{\mathrm{IR}}$ increased significantly from baseline with $10 \mu \mathrm{g} /$ $\mathrm{kg} / \mathrm{min}$ dobutamine, whereas esmolol significantly decreased it. Dobutamine significantly increased ACC compared with the baseline, whereas esmolol significantly

Table 2. Changes in hemodynamic values during inotrope administration

\begin{tabular}{|c|c|c|c|c|c|c|}
\hline & \multicolumn{3}{|c|}{ Dobutamine } & \multicolumn{3}{|c|}{ Esmolol } \\
\hline & Baseline & $5 \mu \mathrm{g} / \mathrm{kg} / \mathrm{min}$ & $10 \mu \mathrm{g} / \mathrm{kg} / \mathrm{min}$ & Baseline & $100 \mu \mathrm{g} / \mathrm{kg} / \mathrm{min}$ & $500 \mu \mathrm{g} / \mathrm{kg} / \mathrm{min}$ \\
\hline HR (bpm) & $87 \pm 11$ & $87 \pm 21$ & $116 \pm 34^{*}$ & $97 \pm 16$ & $92 \pm 12$ & $97 \pm 7$ \\
\hline LVPs (mmHg) & $79 \pm 8$ & $109 \pm 19^{\dagger}$ & $113 \pm 15^{\dagger}$ & $77 \pm 5$ & $71 \pm 5$ & $57 \pm 9^{\ddagger}$ \\
\hline LVEDP (mmHg) & $9 \pm 2$ & $9 \pm 3$ & $9 \pm 3$ & $9 \pm 2$ & $10 \pm 2$ & $14 \pm 1^{\ddagger}$ \\
\hline$+\mathrm{dP} / \mathrm{dt}(\mathrm{mmHg} / \mathrm{sec})$ & $1161 \pm 166$ & $2593 \pm 726^{\ddagger}$ & $3335 \pm 424$ & $1166 \pm 136$ & $926 \pm 153^{\ddagger}$ & $563 \pm 101^{\ddagger}$ \\
\hline$-\mathrm{dP} / \mathrm{dt}(\mathrm{mmHg} / \mathrm{sec})$ & $-1161 \pm 254$ & $-1777 \pm 207^{\ddagger}$ & $-1916 \pm 373^{\ddagger}$ & $-1103 \pm 237$ & $-885 \pm 161^{\dagger}$ & $-435 \pm 100^{\ddagger}$ \\
\hline$\tau(\mathrm{msec})$ & $44 \pm 8$ & $36 \pm 9^{*}$ & $30 \pm 4^{\ddagger}$ & $44 \pm 6$ & $54 \pm 8^{\dagger}$ & $91 \pm 11^{*}$ \\
\hline
\end{tabular}

All data are normally distributed and are described as means \pm SD. HR: heart rate. LVPs: left ventricular systolic pressure. LVEDP: left ventricular end-diastolic pressure. $\mathrm{dP} / \mathrm{dt}$ max: peak positive first derivatives of the $\mathrm{LV}$ pressure. $\mathrm{dP} / \mathrm{dt}$ min: peak negative first derivatives of the LV pressure. ${ }^{*} P<0.05$ vs. baseline, $\dagger P<0.01$ vs. baseline, $\ddagger P<0.001$ vs. baseline.

Table 3. Changes in pulsed-Doppler measurements during inotrope administration

\begin{tabular}{lccccccc}
\hline & \multicolumn{3}{c}{ Dobutamine } & & \multicolumn{3}{c}{ Esmolol } \\
\cline { 2 - 3 } \cline { 6 - 7 } & Baseline & $5 \mu \mathrm{g} / \mathrm{kg} / \mathrm{min}$ & $10 \mu \mathrm{g} / \mathrm{kg} / \mathrm{min}$ & & Baseline & $100 \mu \mathrm{g} / \mathrm{kg} / \mathrm{min}$ & $500 \mu \mathrm{g} / \mathrm{kg} / \mathrm{min}$ \\
\hline E wave $(\mathrm{cm} / \mathrm{sec})$ & $44 \pm 8$ & $63 \pm 8^{\ddagger}$ & $77 \pm 7^{\ddagger}$ & & $49 \pm 8$ & $46 \pm 9$ & $33 \pm 6^{\ddagger}$ \\
A wave $(\mathrm{cm} / \mathrm{sec})$ & $23 \pm 9$ & $28 \pm 13$ & $48 \pm 21^{\ddagger}$ & & $30 \pm 11$ & $25 \pm 10^{\dagger}$ & $22 \pm 9^{\ddagger}$ \\
E/A ratio & $2.4 \pm 1.5$ & $3.0 \pm 2.5$ & $2.5 \pm 2.8$ & & $2.1 \pm 1.5$ & $2.4 \pm 1.9$ & $1.8 \pm 1.0$ \\
IVCT $(\mathrm{msec})$ & $50 \pm 19$ & $15 \pm 17^{\ddagger}$ & $0 \pm 17^{\ddagger}$ & & $46 \pm 24$ & $47 \pm 13$ & $68 \pm 12^{\dagger}$ \\
IVRT (msec) & $34 \pm 17$ & $30 \pm 15$ & $26 \pm 12$ & & $40 \pm 13$ & $34 \pm 13$ & $69 \pm 17^{\ddagger}$ \\
ET (msec) & $216 \pm 20$ & $211 \pm 16$ & $192 \pm 29^{\dagger}$ & & $207 \pm 11$ & $206 \pm 14$ & $190 \pm 12^{\dagger}$ \\
\hline
\end{tabular}

All data are normally distributed and are described as means \pm SD. E wave: peak early diastolic velocity. A wave: peak late diastolic velocity. IVCT: isovolumic contraction time. IVRT: isovolumic relaxation time. ET: ejection time. ${ }^{*} P<0.05$ vs. baseline, ${ }^{\dagger} P<0.01$ vs. baseline, ${ }^{\ddagger} P<0.001$ vs. baseline. 

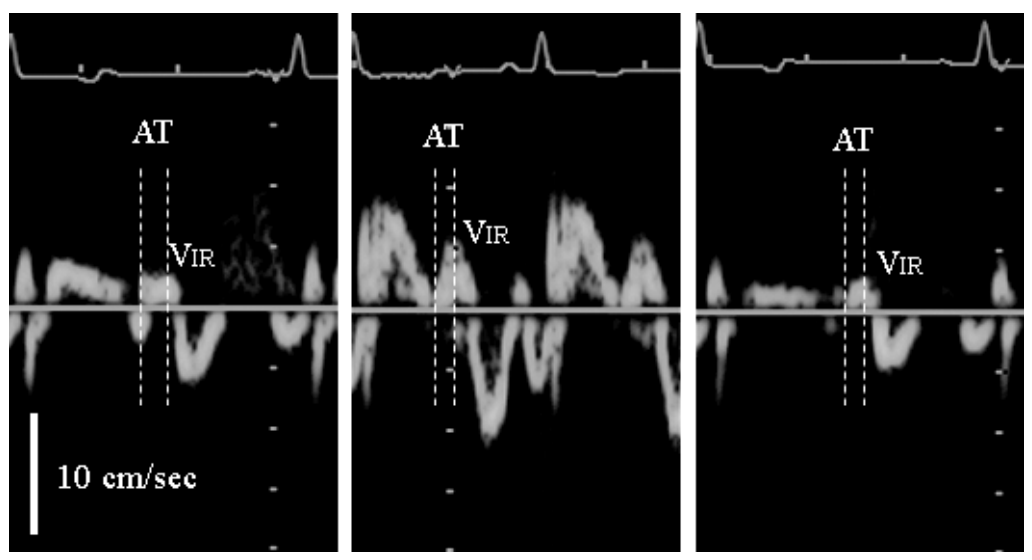

Fig. 2. Representative recordings of mitral annular motion velocity using tissue Doppler imaging (TDI) at baseline (left), with dobutamine (center) and with esmolol (right). AT: acceleration time. $\mathrm{V}_{\mathrm{IR}}$ : annular velocity during isovolumic relaxation.

Table 4. Changes in tissue Doppler imaging (TDI) measurements during inotrope administration

\begin{tabular}{|c|c|c|c|c|c|c|}
\hline & \multicolumn{3}{|c|}{ Dobutamine } & \multicolumn{3}{|c|}{ Esmolol } \\
\hline & Baseline & $5 \mu \mathrm{g} / \mathrm{kg} / \mathrm{min}$ & $10 \mu \mathrm{g} / \mathrm{kg} / \mathrm{min}$ & Baseline & $100 \mu \mathrm{g} / \mathrm{kg} / \mathrm{min}$ & $500 \mu \mathrm{g} / \mathrm{kg} / \mathrm{min}$ \\
\hline $\mathrm{S}^{\prime}(\mathrm{cm} / \mathrm{sec})$ & $5.2 \pm 1.0$ & $10.0 \pm 1.4^{\ddagger}$ & $12.9 \pm 2.0^{*}$ & $5.2 \pm 1.1$ & $4.0 \pm 0.7 *$ & $2.8 \pm 0.5^{\ddagger}$ \\
\hline $\mathrm{E}^{\prime}(\mathrm{cm} / \mathrm{sec})$ & $6.2 \pm 1.0$ & $10.3 \pm 1.2^{\ddagger}$ & $10.8 \pm 1.5^{t}$ & $6.2 \pm 0.9$ & $5.6 \pm 1.1$ & $3.9 \pm 0.8^{\ddagger}$ \\
\hline $\mathrm{A}^{\prime}(\mathrm{cm} / \mathrm{sec})$ & $3.4 \pm 1.1$ & $5.8 \pm 3.4$ & $6.2 \pm 2.5^{*}$ & $3.9 \pm 1.5$ & $3.9 \pm 1.7$ & $3.3 \pm 1.2$ \\
\hline E'/A' ratio & $2.0 \pm 0.9$ & $2.3 \pm 1.3$ & $2.2 \pm 1.4$ & $1.8 \pm 0.7$ & $1.7 \pm 1.0$ & $1.4 \pm 0.8^{*}$ \\
\hline IVCT (msec) & $57 \pm 10$ & $25 \pm 9$ & $17 \pm 9^{*}$ & $51 \pm 12$ & $61 \pm 10$ & $77 \pm 16^{*}$ \\
\hline IVRT (msec) & $72 \pm 16$ & $61 \pm 13$ & $50 \pm 7^{\dagger}$ & $68 \pm 12$ & $84 \pm 18$ & $93 \pm 21^{\dagger}$ \\
\hline $\mathrm{V}_{\mathrm{IR}}(\mathrm{cm} / \mathrm{sec})$ & $3.6 \pm 0.5$ & $5.1 \pm 1.1$ & $7.1 \pm 2.3^{\dagger}$ & $3.7 \pm 0.4$ & $2.8 \pm 0.4^{\dagger}$ & $2.5 \pm 0.3^{\ddagger}$ \\
\hline $\mathrm{ACC}\left(\mathrm{cm} / \mathrm{sec}^{2}\right)$ & $85.4 \pm 17.2$ & $145.1 \pm 47.9^{*}$ & $224.7 \pm 50.6^{+}$ & $104.6 \pm 24.0$ & $70.7 \pm 12.0^{\ddagger}$ & $55.6 \pm 6.4^{\ddagger}$ \\
\hline
\end{tabular}

All data are normally distributed and are described as means \pm SD. E': ventricular early diastolic velocity. A': ventricular late diastolic velocity. S': ventricular systolic velocity. IVCT: isovolumic contraction time. IVRT: isovolumic relaxation time. $\mathrm{V}_{\mathrm{IR}}$ : myocardial velocity during isovolumic relaxation. ACC: myocardial acceleration during isovolumic relaxation. ${ }^{*} P<0.05$ vs. baseline, ${ }^{\dagger} P<0.01$ vs. baseline, ${ }^{\ddagger} P<0.001$ vs. baseline.

decreased ACC.

The results of regression analysis of the echocardiographic measurements and $\mathrm{dP} / \mathrm{dt} \min$ or $\tau$ are described in Figs. 3 and 4 and Table 5, respectively. The PD-derived IVRT was significantly correlated with $\mathrm{dP} / \mathrm{dt} \min$ and $\tau$ ( $r=$ -0.60 and 0.62$)$. The $\mathrm{dP} / \mathrm{dt}$ min was strongly correlated with the TDI-derived $\mathrm{V}_{\text {IR }}$ and ACC ( $r=0.85$ and 0.84$)$, whereas it was weakly correlated with the IVRT $(r=0.43)$. Similarly, $\tau$ was strongly correlated with the TDI-derived IVRT ( $r=$ 0.74 ), whereas it was weakly correlated with $\mathrm{V}_{\text {IR }}$ and ACC $(r=0.49$ and -0.52$)$. Stepwise regression analysis showed that the E' velocity $(F=41.1)$, ACC $(F=5.6)$, PD-derived IVRT $(F=4.6)$ and heart rate $(F=2.8)$ could predict $\mathrm{dP} / \mathrm{dt}$ $\min \left(r=0.94, r^{2}=0.88, P<0.001\right)$. In contrast, the PD-derived IVRT $(F=21.0)$, TDI-derived IVRT $(F=7.5)$, E' velocity $(F=5.3)$ and $\mathrm{E} / \mathrm{A}$ ratio $(F=4.8)$ were equally able to predict $\tau$ $\left(r=0.88, r^{2}=0.78, P<0.001\right)$.

\section{DISCUSSION}

Measurements of diastolic function during isovolumic relaxation have been used to assess active or intrinsic relaxation properties in human patients with heart failure $[1,10$, 27]. Several studies have reported elevated LV filling pressures in patients with chronic heart failure, despite having normal LV systolic function $[16,26,30]$. In addition, LV diastolic function frequently becomes impaired before systolic function in human patients with heart disease [18]. Furthermore, diastolic dysfunction has been reported to be evident in dogs with dilated cardiomyopathy [4-6, 24]. In the present study, we investigated the feasibility of using the mitral annulus-derived time interval, velocity and acceleration obtained from pulsed-TDI during isovolumic relaxation in dogs.

TDI can be used to calculate the IVCT and IVRT over a single cardiac cycle under normal conditions $[2,3,14]$. In addition, TDI provides the timing elements necessary to cal- 

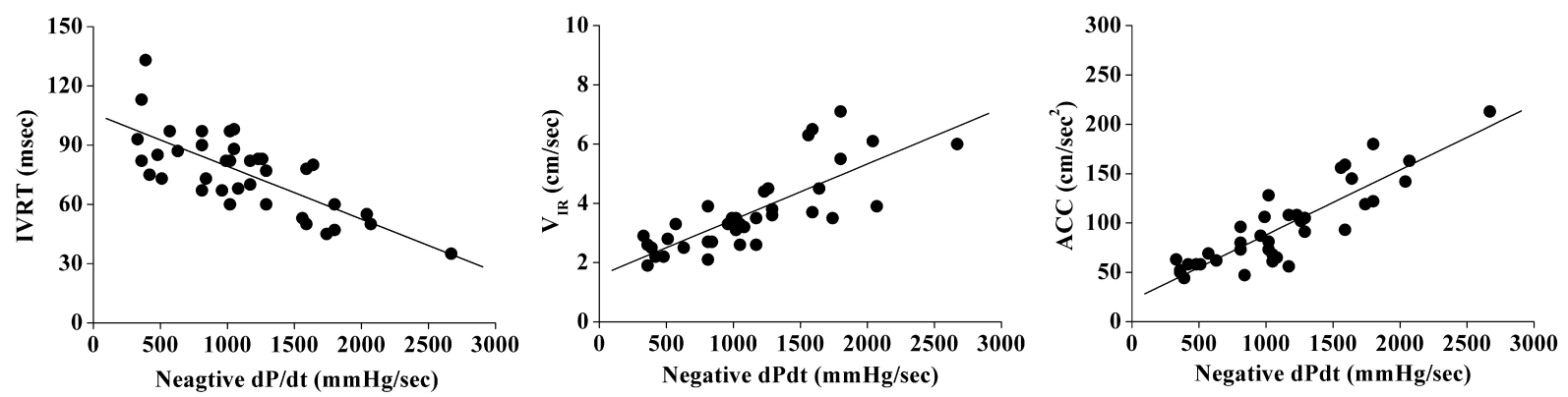

Fig. 3. Correlations between the negative first derivative of the left ventricular pressure (dP/dt min) and tissue Doppler imaging (TDI)derived IVRT (left), $\mathrm{V}_{\text {IR }}$ (center) and ACC (right). Significant correlations were observed between $\mathrm{dP} / \mathrm{dt}$ min and the IVRT, $\mathrm{V}_{\text {IR }}$, and ACC (all $P<0.001$ ). IVRT: isovolumic relaxation time. $\mathrm{V}_{\mathrm{IR}}$ : annular velocity during isovolumic relaxation. ACC: annular acceleration during isovolumic relaxation.
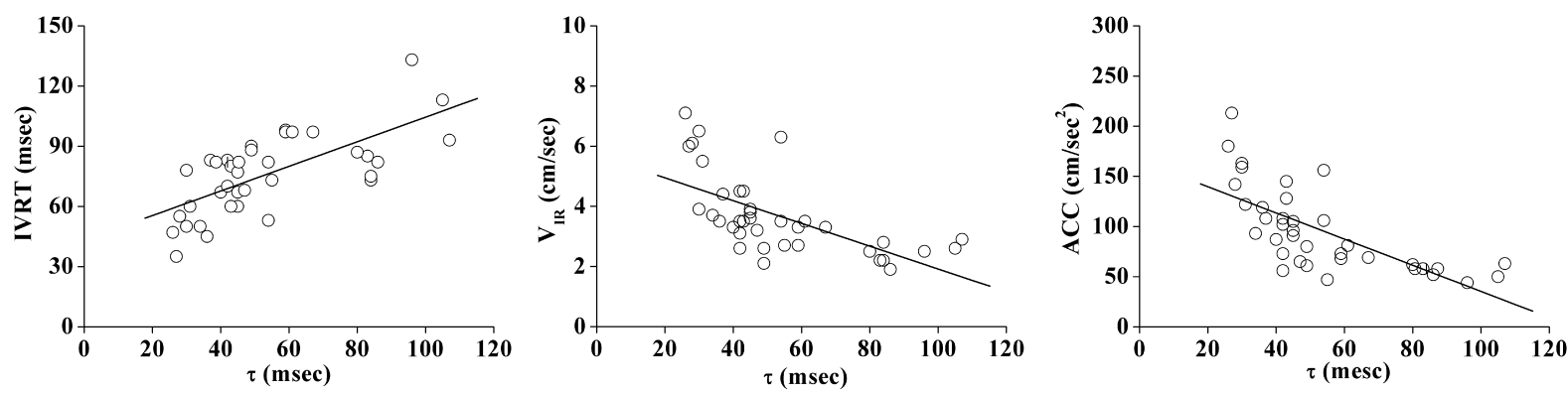

Fig. 4. Correlations between the time constant of isovolumic relaxation $(\tau)$ and tissue Doppler imaging (TDI)-derived IVRT (left), $\mathrm{V}_{\mathrm{IR}}$ (center) or ACC (right). Significant correlations were observed between $\tau$ and the IVRT, $\mathrm{V}_{\mathrm{IR}}$ and ACC $(P<0.001$, respectively). IVRT: isovolumic relaxation time. $\mathrm{V}_{\mathrm{IR}}$ : annular velocity during isovolumic relaxation. ACC: annular acceleration during isovolumic relaxation.

Table 5. Correlations between standard pulsed-Doppler (PD) or tissue Doppler imaging (TDI) measurements and the negative first derivative of the left ventricular pressure $(\mathrm{dP} / \mathrm{dt} \min )$ or time constant of isovolumic relaxation $(\tau)$

\begin{tabular}{lcccccc}
\hline \multirow{2}{*}{ PD } & \multicolumn{2}{c}{$\mathrm{dP} / \mathrm{dt} \min$} & & \multicolumn{2}{c}{$\tau$} \\
\cline { 2 - 3 } \cline { 5 - 6 } & $r$ & $P$ & & $r$ & $P$ \\
\hline E wave & 0.85 & 0.001 & & -0.29 & $\mathrm{NS}$ \\
A wave & 0.63 & 0.001 & & 0.03 & $\mathrm{NS}$ \\
E/A ratio & 0.14 & $\mathrm{NS}$ & & -0.25 & $\mathrm{NS}$ \\
IVRT & -0.60 & 0.001 & & 0.62 & 0.001 \\
\hline TDI & \multicolumn{2}{c}{$\mathrm{dP} / \mathrm{dt}$ min } & & \multicolumn{2}{c}{$\tau$} \\
\cline { 2 - 3 } \cline { 5 - 6 } & \multicolumn{2}{c}{$r$} & $P$ & & $r$ & $P$ \\
\hline E' wave & 0.92 & 0.001 & & -0.61 & 0.001 \\
A' wave & 0.34 & 0.05 & & 0.10 & $\mathrm{NS}$ \\
E'/A' ratio & 0.50 & 0.01 & & -0.31 & $\mathrm{NS}$ \\
E/E' ratio & -0.19 & $\mathrm{NS}$ & & 0.08 & $\mathrm{NS}$ \\
IVRT & -0.43 & 0.01 & & 0.74 & 0.001 \\
V & 0.85 & 0.001 & & -0.49 & 0.01 \\
ACC & 0.84 & 0.001 & & -0.52 & 0.001 \\
\hline
\end{tabular}

culate IVRT on a beat-to-beat basis [3, 14]. IVRT, which can provide information related to $\mathrm{LV}$ diastolic function, is correlated with $\mathrm{dP} / \mathrm{dt}$ min and $\tau[12,13,15,16,22]$. Several studies have demonstrated that the TDI-derived IVRT is prolonged in patients with LV diastolic dysfunction $[9,17$, 28]. Our results demonstrate that pulsed-TDI-derived IVRT is significantly shortened by dobutamine, but significantly prolonged by esmolol. Pulsed-TDI-derived IVRT was strongly correlated with $\mathrm{dP} / \mathrm{dt}$ min and $\tau$, which is consistent with previous reports $[12,13,15,16,22]$.

$\mathrm{V}_{\mathrm{IR}}$ has been demonstrated as a positive velocity spike during isovolumic relaxation $[12,13,19]$. When comparing different LV segments, TDI-derived positive $V_{I R}$ can be used as an indicator of coronary artery disease in humans [25]. In addition, the strain rate imaging-derived peak myocardial acceleration during IVRT is correlated with $\mathrm{LV} \mathrm{dP/}$ dt min in sheep $[12,13]$. Our study showed that the TDIderived $V_{I R}$ is a positive wave in the $\mathrm{LV}$ free wall, which is consistent with previous reports. In addition, our results demonstrate that $\mathrm{V}_{\mathrm{IR}}$ values derived from the mitral annulus are increased significantly with dobutamine, but decreased significantly with esmolol and are strongly correlated with $\mathrm{dP} / \mathrm{dt}$ min and $\tau$. Our data indicate that pulsed-TDI-derived positive $V_{I R}$ measurements are a useful parameter for assessing LV relaxation in dogs.

Assessing myocardial acceleration during the isovolumic phase may be an attractive method to investigate cardiac function. For example, acceleration during isovolumic contraction is a good indicator of global LV systolic function in pigs, independent of preload and afterload changes and within a physiological range [31]. However, assessment of myocardial acceleration during isovolumic contraction seems to be very limited because it does not provide further 
information about regional contractility in dogs with myocardial ischemia [20]. This conflict may be explained by methodological differences. Vogel et al. [31] measured global cardiac function by conductance catheterization, whereas Lyseggen et al. [20] measured regional myocardial motion by sonomicrometry.

Previous studies using strain rate imaging show that ACC is the acceleration of the myocardial velocity during isovolumic relaxation $[12,13]$. ACC values derived from strain rate imaging are significantly affected by adrenergic agents and correlate with ventricular diastolic function in sheep $[12,13]$. Our study showed that the ACC values derived from TDI were significantly increased by dobutamine, but significantly decreased by esmolol, and were strongly correlated with $\mathrm{dP} / \mathrm{dt} \min$ and $\tau$. These results indicate that pulsed-TDI-derived ACC measurements can be used to assess $\mathrm{LV}$ relaxation in dogs.

Several limitations of the present study should be noted, including the confounding influence of LV translation and rotation during relaxation and our ability to determine the velocity at only a single point within the myocardium. In our study, the LV free wall-derived $V_{\text {IR }}$ was a positive wave. However, there is some conflicting data indicating that $V_{I R}$ is a negative wave or biphasic wave in dogs and humans, but that large positive $V_{\text {IR }}$ values may indicate dyskinesis in the ischemic myocardium $[8,25]$. These results may be explained by methodological differences such as in animal species, instruments and methods (strain rate imaging or TDI). Furthermore, septal TDI-derived $\mathrm{V}_{\mathrm{IR}}$ and ACC may demonstrate different results under the same conditions. We cannot exclude the possibility that general anesthesia might have affected our echocardiographic measurements. Given that $\mathrm{V}_{\mathrm{IR}}$ and IVRT are influenced by several factors, including age, preload condition and heart rate $[19,22]$, these values should be interpreted with caution. Finally, dogs with chronic heart disease may demonstrate a very different response under the same conditions.

Our data demonstrate that pulsed-TDI-derived $\mathrm{V}_{\mathrm{IR}}$ and ACC measurements reflect invasive measurements of LV relaxation in normal dogs. Therefore, pulsed-TDI-derived $\mathrm{V}_{\text {IR }}$ and ACC values may be good indicators for noninvasive LV diastolic assessment. Additional studies are required to assess the practical utility of these approaches and to investigate whether the present findings are valid in dogs with heart disease.

\section{REFERENCES}

1. Beuckelmann, D.J., Nabauer, M. and Erdmann, E. 1992. Intracellular calcium handling in isolated ventricular myocytes from patients with terminal heart failure. Circulation 85: 10461055.

2. Bruch, C., Schmermund, A., Marin, D., Katz, M., Bartel, T., Schaar, J. and Erbel, R. 2000. Tei-index in patients with mildto-moderate congestive heart failure. Eur. Heart J. 21: 18881895.

3. Cannesson, M., Jacques, D., Pinsky, M.R. and Gorcsan, J, 3rd. 2006. Effects of modulation of left ventricular contractile state and loading conditions on tissue Doppler myocardial performance index. Am. J. Physiol. Heart Circ. Physiol. 290: H19521959.

4. Chetboul, V., Carlos, C., Blot, S., Thibaud, J.L., Escriou, C., Tissier, R., Retortillo, J.L. and Pouchelon, J.L. 2004. Tissue Doppler assessment of diastolic and systolic alterations of radial and longitudinal left ventricular motions in Golden Retrievers during the preclinical phase of cardiomyopathy associated with muscular dystrophy. Am. J. Vet. Res. 65: 13351341.

5. Chetboul, V., Gouni, V., Sampedrano, C.C., Tissier, R., Serres, F. and Pouchelon, J.L. 2007. Assessment of regional systolic and diastolic myocardial function using tissue Doppler and strain imaging in dogs with dilated cardiomyopathy. J. Vet. Intern. Med. 21: 719-730.

6. Chetboul, V., Sampedrano, C.C., Testault, I. and Pouchelon, J.L. 2004. Use of tissue Doppler imaging to confirm the diagnosis of dilated cardiomyopathy in a dog with equivocal echocardiographic findings. J. Am. Vet. Med. Assoc. 225: 1877-1880.

7. Cheung, M.M., Smallhorn, J.F., Redington, A.N. and Vogel, M. 2004. The effects of changes in loading conditions and modulation of inotropic state on the myocardial performance index: comparison with conductance catheter measurements. Eur. Heart J. 25: 2238-2242.

8. Edvardsen, T., Urheim, S., Skulstad, H., Steine, K., Ihlen, H. and Smiseth, O.A. 2002. Quantification of left ventricular systolic function by tissue Doppler echocardiography: added value of measuring pre- and postejection velocities in ischemic myocardium. Circulation 105: 2071-2077.

9. Gullulu, S., Kaderli, A.A., Ekbul,A., Ozdemir, B., Baran, I., Gullulu, M., Ediz, B., Cordan, J. and Yurtkuran, M. 2005. Tissue Doppler echocardiography and myocardial performance index in patients with scleroderma. J. Int. Med. Res. 33: $417-$ 424.

10. Gwathmey, J.K., Copelas, L., MacKinnon, R., Schoen, F.J., Feldman, M.D., Grossman, W. and Morgan, J.P. 1987. Abnormal intracellular calcium handling in myocardium from patients with end-stage heart failure. Circ. Res. 61: 70-76.

11. Harada, K., Tamura, M., Toyono, M. and Yasuoka, K. 2002. Effect of dobutamine on a Doppler echocardiographic index of combined systolic and diastolic performance. Pediatr. Cardiol. 23: 613-617.

12. Hashimoto, I., Bhat, AH., Li, X., Jones, M., Davies, C.H., Swanson, J.C., Schindera, S.T. and Sahn, D.J. 2004. Tissue Doppler-derived myocardial acceleration for evaluation of left ventricular diastolic function. J. Am. Coll. Cardiol. 44: 14591466.

13. Hashimoto, I., Li, X.K., Bhat, A.H., Jones, M. and Sahn, D.J. 2005. Quantitative assessment of regional peak myocardial acceleration during isovolumic contraction and relaxation times by tissue Doppler imaging. Heart 91: 811-816.

14. Hori, Y., Kano, T., Hoshi, F. and Higuchi, S. 2007. Relationship between tissue Doppler-derived RV systolic function and invasive hemodynamic measurements. Am. J. Physiol. Heart Circ. Physiol. 293: H120-125.

15. Hori, Y., Kunihiro, S., Hoshi, F. and Higuchi, S. 2007. Comparison of the myocardial performance index derived by use of pulsed Doppler echocardiography and tissue Doppler imaging in dogs with volume overload. Am. J. Vet. Res. 68: 1177-1182.

16. Kasner, M., Westermann, D., Steendijk, P. Gaub, R., Wilkenshoff, U., Weitmann, K., Hoffmann, W., Poller, W., Schultheiss, H.P., Pauschinger, M. and Tschope, C. 2007. Utility of 
Doppler echocardiography and tissue Doppler imaging in the estimation of diastolic function in heart failure with normal ejection fraction: a comparative Doppler-conductance catheterization study. Circulation 116: 637-647.

17. Kjaergaard, J., Hassager, C., Oh, J.K., Kristensen, J.H., Berning, J. and Sogaard, P. 2005. Measurement of cardiac time intervals by Doppler tissue M-mode imaging of the anterior mitral leaflet. J. Am. Soc. Echocardiogr. 18: 1058-1065.

18. Kondo, H., Masuyama, T., Ishihara, K., Mano, T., Yamamoto, K., Naito, J., Nagano, R., Kishimoto, S., Tanouchi, J., Hori, M. et al. 1995. Digital subtraction high-frame-rate echocardiography in detecting delayed onset of regional left ventricular relaxation in ischemic heart disease. Circulation 91: 304-312.

19. Larrazet, F., Pellerin, D., Fournier, C., Witchitz, S. and Veyrat, C. 1997. Right and left isovolumic ventricular relaxation time intervals compared in patients by means of a single-pulsed Doppler method. J. Am. Soc. Echocardiogr. 10: 699-706.

20. Lind, B., Nowak, J., Cain, P., Quintana, M. and Brodin, L.A. 2004. Left ventricular isovolumic velocity and duration variables calculated from colour-coded myocardial velocity images in normal individuals. Eur. J. Echocardiogr. 5: 284-293.

21. Lyseggen, E., Rabben, S.I., Skulstad, H., Urheim, S., Risoe, C. and Smiseth, O.A. 2005. Myocardial acceleration during isovolumic contraction: relationship to contractility. Circulation 111: $1362-1369$.

22. Matsumura, Y., Elliott P.M., Virdee, M.S., Sorajja, P., Doi, Y. and McKenna, W.J. 2002. Left ventricular diastolic function assessed using Doppler tissue imaging in patients with hypertrophic cardiomyopathy: relation to symptoms and exercise capacity. Heart 87: 247-251.

23. Myreng, Y. and Smiseth, O.A. 1990. Assessment of left ventricular relaxation by Doppler echocardiography. Comparison of isovolumic relaxation time and transmitral flow velocities with time constant of isovolumic relaxation. Circulation 81: 260-266.

24. Nagueh, S.F,, Sun, H., Kopelen, H,A., Middleton, K.J. and Khoury, D.S. 2001. Hemodynamic determinants of the mitral annulus diastolic velocities by tissue Doppler. J. Am. Coll.
Cardiol. 37: 278-285.

25. O'Sullivan, M.L., O'Grady, M.R. and Minors, S.L. 2007. Assessment of diastolic function by Doppler echocardiography in normal Doberman Pinschers and Doberman Pinschers with dilated cardiomyopathy. J. Vet. Intern. Med. 21: 81-91.

26. Onishi, T., Uematsu, M., Nanto, S., Iida, O., Morozumi, T., Kotani, J., Awata, M. and Nagata, S. 2007. Positive isovolumic relaxation velocity detected by a spectral tissue Doppler mapping technique as an indicator of coronary artery disease: a prospective study. J. Am. Soc. Echocardiogr. 20: 158-164.

27. Packer, M. 1990. Abnormalities of diastolic function as a potential cause of exercise intolerance in chronic heart failure. Circulation 81: III78-86.

28. Parker, J.D., Landzberg, J.S., Bittl, J.A., Mirsky, I. and Colucci, W.S. 1991. Effects of beta-adrenergic stimulation with dobutamine on isovolumic relaxation in the normal and failing human left ventricle. Circulation 84: 1040-1048.

29. Tavil, Y., Ozturk, M.A., Sen, N., Kaya. M.G., Hizal, F., Poyraz, F., Turfan, M., Onder, M., Gurer, M.A. and Cengel, A. 2008. The assessment of cardiac functions by tissue Dopplerderived myocardial performance index in patients with Behcet's disease. Clin. Rheumatol. 27: 309-314.

30. Teshima, K., Asano, K., Iwanaga, K., Koie, H., Uechi, M., Kato, Y., Kutara, K., Kanno, N., Seki, M., Edamura, K., Hasegawa, A. and Tanaka, S. 2007. Evaluation of left ventricular Tei index (index of myocardial performance) in healthy dogs and dogs with mitral regurgitation. J. Vet. Med. Sci. 69: 117123.

31. Vasan, R.S., Benjamin, E.J. and Levy, D. 1995. Prevalence, clinical features and prognosis of diastolic heart failure: an epidemiologic perspective. J. Am. Coll. Cardiol. 26: 1565-1574.

32. Vogel, M., Cheung, M.M., Li, J., Kristiansen, S.B., Schmidt, M.R., White, P.A., Sorensen, K. and Redington, A.N. 2003. Noninvasive assessment of left ventricular force-frequency relationships using tissue Doppler-derived isovolumic acceleration: validation in an animal model. Circulation 107: 16471652 . 